\section{$\underset{\substack{\text { hommes } \\ \text { \& migrations }}}{ }$}

\section{Hommes \& migrations}

Revue française de référence sur les dynamiques

migratoires

$1284 \mid 2010$

Migrations et environnement

\title{
Kebir Mustapha Ammi, Les Vertus immorales
}

Gallimard, 2009, 210 pages, 17,50 euros

\section{Mustapha Harzoune}

\section{(2) OpenEdition}

\section{Journals}

\section{Édition électronique}

URL : http://journals.openedition.org/hommesmigrations/1287

DOI : 10.4000/hommesmigrations. 1287

ISSN : 2262-3353

Éditeur

Musée national de l'histoire de l'immigration

Édition imprimée

Date de publication : 1 mars 2010

Pagination : 210

ISSN : 1142-852X

\section{Référence électronique}

Mustapha Harzoune, « Kebir Mustapha Ammi, Les Vertus immorales», Hommes \& migrations [En ligne], 1284 | 2010, mis en ligne le 29 mai 2013, consulté le 22 septembre 2020. URL : http:// journals.openedition.org/hommesmigrations/1287 ; DOI : https://doi.org/10.4000/ hommesmigrations. 1287

Ce document a été généré automatiquement le 22 septembre 2020.

Tous droits réservés 


\title{
Kebir Mustapha Ammi, Les Vertus immorales
}

Gallimard, 2009, 210 pages, 17,50 euros

\author{
Mustapha Harzoune
}

\section{RÉFÉRENCE}

Kebir Mustapha Ammi, Les Vertus immorales, Gallimard, 2009, 210 pages, 17,50 euros

1 Kebir Mustapha Ammi est un humaniste, parti hier sur les traces de saint Augustin, du mystique Hallaj ou de l'émir Abd-el-Kader. À cheval par sa parentèle sur le Maroc où il est né et l'Algérie paternelle. L'émigration a fait de lui un de ces êtres modernes attachés à un ailleurs, le Maroc, et un ici, la France, où il vit. Professeur d'anglais, il voyage entre le Vieux Continent et les États-Unis. Citoyen du monde, si cela a un sens, il habite plus sûrement les mots, ceux de l'écriture comme ceux prononcés en arabe, en français ou en anglais. Kebir Ammi conte l'histoire d'un drôle de bonhomme vivant au $\mathrm{XVI}^{\mathrm{e}}$ siècle et qui, pour survivre et déjouer les pièges nombreux de l'existence, doit tromper, voler, assassiner et trahir. L'épopée de Moumen traverse un siècle où l'Europe fait main basse sur le Nouveau Continent, où l'islam et la chrétienté se jaugent, se défient et s'affrontent, où la civilisation occidentale assoit sa supériorité, son "mépris civilisé", sur le reste des cultures humaines.

2 En exergue, l'auteur a choisi cette citation de Dante : "Vous n'avez pas été faits pour vivre comme des bêtes, /Mais pour suivre vertu et connaissance". Et c'est comme un miroir à l'existence de Moumen, qui, parti enfant de Salé, en terre marocaine, passera par l'Espagne, avant d'être le premier Maure à fouler le continent américain découvert quelques trois décennies plus tôt par le Génois, Christophe Colomb. Des années plus tard et une foule d'aventures derrière lui, il reviendra en Europe où il sera, un temps, le loyal conseiller du très catholique roi d'Espagne. Au soir de sa vie, il entreprendra un voyage dans la France voisine qui fourbit ses armes pour les prochaines guerres de religion. Il en reviendra métamorphosé.Ce chemin s'ouvre avec un vieux maître, 
délicieux érudit, misanthrope, qui avait quitté l'Église "avec la conviction que les hommes n'ont créé les religions que pour tromper leurs semblables" et se referme sur un manuscrit où plane l'esprit de Murcie, la ville d'Ibn Arabî.

3 Les résonances avec le monde contemporain sont nombreuses : le passage du détroit de Gibraltar, l'islam, objet de peur et de suspicion, les "chimères" des fanatismes et des croyances mais aussi l'émigration comme bifurcation fondatrice : "La sortie en mer, pour gagner le grand large, fut pour moi une deuxième naissance. Je réalisai qu'une vie s'achevait et qu'une autre commençait. Plus rien ne serait comme avant. Tout ce que je vivrais désormais sur la terre à venir, cette nouvelle rive, serait comme l'enfance d'une nouvelle vie."

4 Kebir Ammi poursuit sa quête, celle de dresser des passerelles entre les hommes et les cultures. Les vertus immorales de ce Moumen déconcerteront. C'est dans les creux et les silences de ce récit que se nichent les "vertus et connaissances" recherchées. Et dans la langue de l'auteur. Classique et chatoyante, elle se déploie tel un long ruisseau qui serpente, paisiblement, entre les récifs. 